\title{
Optical and Physical Properties of Methyltrimethoxysilane Transparent Film Incorporated with Nanoparticles
}

\author{
W. Ahliah Ismail, Zainal Abidin Ali, and R. Puteh \\ Corrosion and Coating Laboratory, Department of Physics, Universiti Malaya, 50603 Kuala Lumpur, Malaysia \\ Correspondence should be addressed to Zainal Abidin Ali, zaba_87@yahoo.com
}

Received 29 October 2012; Revised 9 December 2012; Accepted 9 December 2012

Academic Editor: Wen-Hua Sun

Copyright ( $) 2012$ W. Ahliah Ismail et al. This is an open access article distributed under the Creative Commons Attribution License, which permits unrestricted use, distribution, and reproduction in any medium, provided the original work is properly cited.

\begin{abstract}
Methyltrimethoxysilane has been used as a base in the formation of transparent sol-gel coatings on glass substrates. Several types of alcohol were used as solvents in order to obtain the highest transparency and scratch hardness of the film. The coating cures at room temperature $\left(26^{\circ} \mathrm{C}\right)$. The clarity of the coated film on the glass substrate was measured using haze meter. The best formulation based on the lowest haze values and light diffusion is the ratio of $1: 1$ trimethoxy silane to N-propanol. The haze value obtained for this system is 0.86 , and the light diffusion was measured at $0.77 \%$. Tack-free time and hardness were within acceptable value. Nanoparticles of silver, zinc oxide, and titanium dioxide were incorporated into the coating system from $0.5 \%$ to $2.5 \%$ by weight, and the haze values of the dried film were measured. The highest transparency was obtained from the samples that were mixed with $0.5 \%$ silver. The haze value for this sample is of 0.5 .
\end{abstract}

\section{Introduction}

Coatings on glass are applied in order to modify its functional behaviours. Properties such as protective coating, antireflex, antiglare, antistatic, or modification in dielectric and transmission properties are some of the many functional modifications that can enhance value-added applications to the glass. Various monomers have been used for these purposes. Methyltrimethoxysilane for instance. This is because of its optical transparent [1], antibacterial [2], and selfcleaning behaviour [3].

One way to prepare the coatings is the sol-gel process. It is a simple technique and has been used to produce film with high optical transparency [4] and low thermal conductivity [5] and presently widely used in architectural window [68]. Due to its simplicity, sol-gel coatings are widely used in those related with optical semiconductor [9], protective [1012], and sensing application [13]. Typically, sol-gel coated surfaces need a separate curing treatment by heating at temperatures between $100^{\circ} \mathrm{C}$ and $500^{\circ} \mathrm{C}$ [14-16]. This treatment, however, increases the manufacturing costs, especially when sol-gel coating is applied to already existing production chains. Sol-gel coatings of low temperature processing have shown good adherence to the substrates (glass, ceramics composites, etc.) and possibility to prepare multilayered coatings due to their low viscosity. The drawback of the sol-gel processing other than cost is the shrinkage that accompanies drying and sintering and processing time [17]. These problems however can be addressed by having a careful choice of solvent used.

Solvent is a very important component in the sol-gel process. It is used in sol-gel synthesis as media for the hydrolysis and condensation of precursors as well as to control the concentrations of reactants, which influence the solidifications kinetics. By carefully choosing the solvent and its unique properties (i.e., dielectric constant, surface tension, and dipole moment), parameters such as the rate of gel formation, gel structure, and drying behavior can be changed [18]. Therefore, in order to investigate the effect of solvent on the optical and physical properties of methyltrimethoxy silane transparent film, a series of different types of alcohols were tested and used as the solvents. Methyltrimethoxy silane was chosen as the monomer due to its low viscosity. The objective is to obtain thin layer of clear coating on the glass substrate that is cured and hardened at room temperature without heat treatment. The 
TABLE 1: The sol-gel formulation using N-propanol as solvent.

\begin{tabular}{|c|c|c|c|c|c|c|c|}
\hline Sample & $0 \mathrm{~N}$ & $20 \mathrm{~N}$ & $40 \mathrm{~N}$ & $50 \mathrm{~N}$ & $60 \mathrm{~N}$ & $80 \mathrm{~N}$ & $90 \mathrm{~N}$ \\
\hline N-Propanol & 0 & 20 & 40 & 50 & 60 & 80 & 90 \\
\hline Methyl trimethoxy silane & 100 & 80 & 60 & 50 & 40 & 20 & 10 \\
\hline Appearance & Cracking & Cracking & Clear & Clear & Hazy & Hazy & Hazy \\
\hline
\end{tabular}

TABLE 2: The sol-gel formulation using ethanol as solvent.

\begin{tabular}{|c|c|c|c|c|c|c|c|}
\hline Sample & $0 \mathrm{E}$ & $20 \mathrm{E}$ & $40 \mathrm{E}$ & $50 \mathrm{E}$ & $60 \mathrm{E}$ & $80 \mathrm{E}$ & $90 \mathrm{E}$ \\
\hline Ethanol & 0 & 20 & 40 & 50 & 60 & 80 & 90 \\
\hline Methyl trimethoxy silane & 100 & 80 & 60 & 50 & 40 & 20 & 10 \\
\hline Appearance & Cracking & Cracking & Clear & Clear & Hazy & Hazy & Hazy \\
\hline
\end{tabular}

possible application for this type of coating system is to have a value-added function when functioning agents were mixed with the coating system without interfering with the original appearance of the substrate. Therefore, the coating should appear to be very transparent with an acceptable tackfree time for the application process and hardness for the durability.

\section{Experimental}

Glass slides with $2 \mathrm{~mm}$ thickness were cleaned with water and finally with acetone to remove the grease and contaminants on the surface. The solvents and methyltrimethoxy silane $\left(\mathrm{Si}-\mathrm{CH}_{3}-\left(\mathrm{OCH}_{3}\right)_{3}\right)$ were mixed in a beaker with the ratio of $1: 1$ to study the compatibility of the substances. No modification has been made on the chemicals that were purchased from the supplier. Nitric acid was diluted to 5\% with the $\mathrm{pH}$ of 0.1 added to the mixture by $10 \%$ wt as a catalyst. In the experiment with nanoparticles, the particles were added from $0.5 \%$ to $2.5 \%$ by weight into the coating mixture with vigorous stirring to maintain the uniformity of the coating. The mixtures were stirred for 30 seconds and coated on the prepared glass slides using melamine sponge $(1.5 \mathrm{~cm} \times 1.5 \mathrm{~cm} \times 4 \mathrm{~cm})$. The coated samples were dried in the room temperature at $26^{\circ} \mathrm{C}$ and absolute humidity of $30 \%$. The wet coating was coated on the glass slides of $2 \mathrm{~mm}$ thickness $(2.5 \mathrm{~cm} \times 7.5 \mathrm{~cm})$ using a melamine sponge. $0.5 \mathrm{~mL}$ of the coating was used for every slide, and the coating was spread with a single stroke to maintain the same thickness of the coating. The coating process was carried out in room temperature at $26^{\circ} \mathrm{C}$ and absolute humidity of $30 \%$. These two factors need to be constant throughout the experiment. The dried samples were measured for transparency using haze meter with D65 illumination light at room temperature. Mitsubishi pencil scratch tester was used with the load of $1 \mathrm{~kg}$ to measure the scratch hardness of the coated films on the glass substrate.

\section{Results and Discussions}

Solvents are added into the system to prevent liquid-liquid phase separation during the initial stages of the hydrolysis and to control the concentration of silicate and water that
Tack-free (mins)

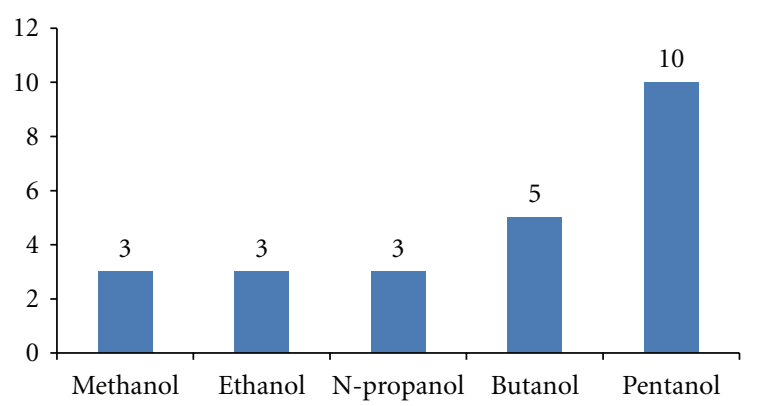

FIgure 1: The tack-free time in the room temperature $\left(26^{\circ} \mathrm{C}\right.$ temperature and $30 \%$ absolute humidity).

influence the gelation. In this study, we are focusing on the common alcohols used as solvents in sol-gel processing. The availability of labile protons in protic solvents such as water and alcohols influences the extent of the reverse reactions, reesterification, or siloxane bond alcoholysis or hydrolysis [19].

Tack-free time is very important especially during the coating process. The tack-free time remains constant for sample that was mixed with methanol, ethanol, and $\mathrm{N}$ propanol. However, longer tack-free time was obtained from the samples that were mixed with pentanol due to the higher boiling point and lower evaporation rate (Figure 1).

Pencil scratch hardness is widely used in measuring the hardness of the coating film formed. There are no significant changes in hardness values of the coatings when different solvent was used in the experiment. Thus, the type of solvents does not affect the hardness of the dried coatings (Figure 2(a)).

The lowest haze value was obtained from sample that was mixed with $\mathrm{N}$-propanol (Figure 2(b)). Higher haze values were obtained from samples that were mixed with butanol and pentanol. Longer tack-free time resulted in more dust particles to stick onto the coatings. N-propanol also showed the lowest percentage of light diffused (Figure 3).

Based on the results previously mentioned, N-propanol has shown the most promising solvents for the coatings based on the compatibility compared to the other alcohols 


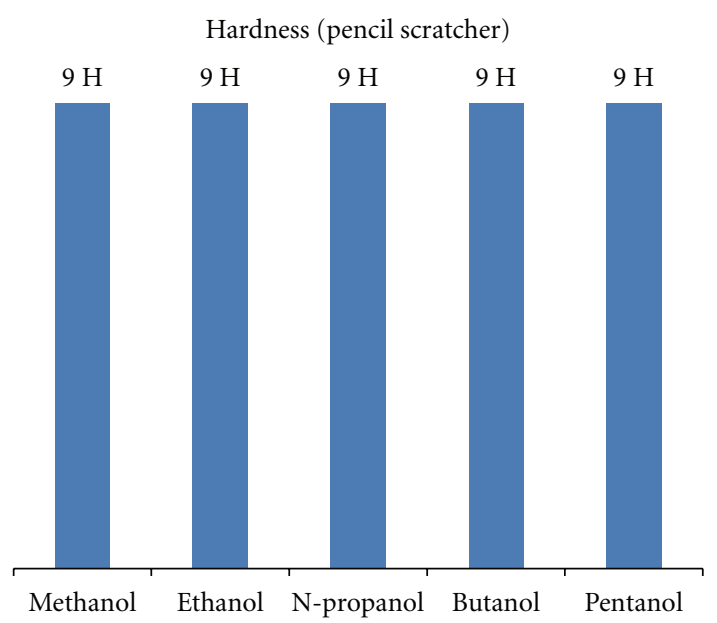

(a)
Haze value

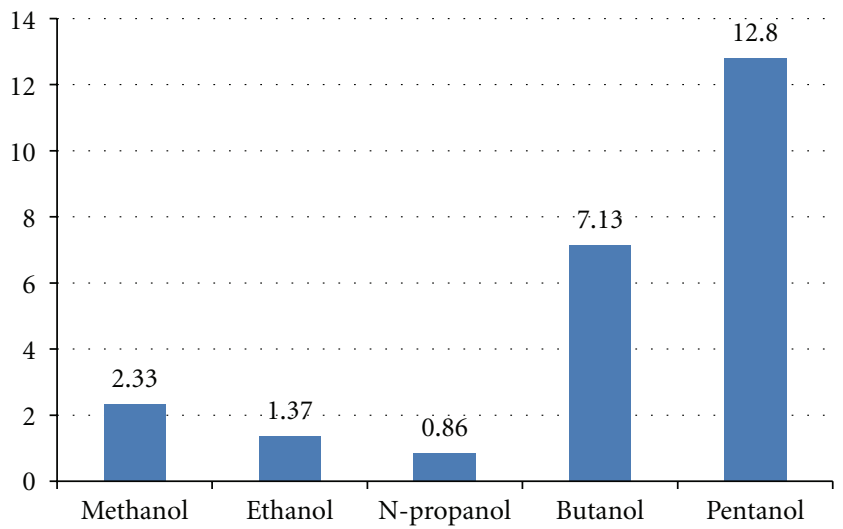

(b)

FIgURE 2: (a) The scratch hardness values based on the Mitsubishi pencil scratcher and (b) the haze values of thee coated samples.

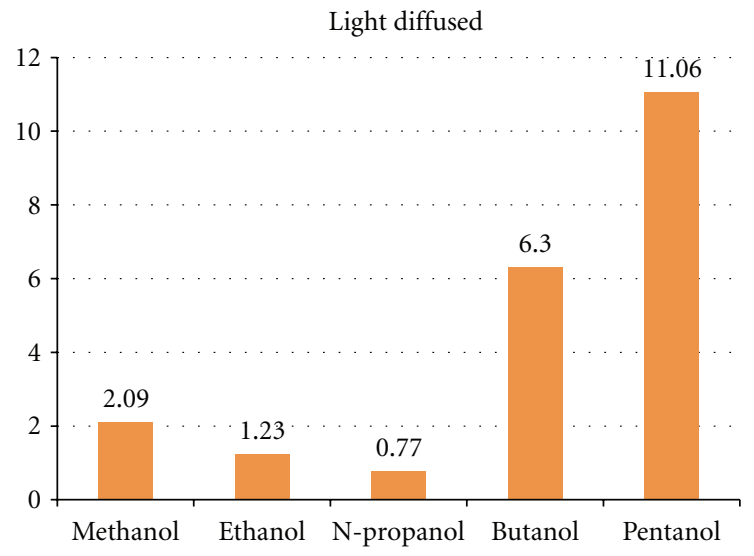

Figure 3: Percentage of light diffused.

in the studies. The next approach was the comparison of $\mathrm{N}$-propanol to the ethanol with different percentage of solvents into the binder system. The coating was mixed according to Tables 1 and 2. Ethanol was chosen as the comparison because it is the most common solvent used in the industry. For both solvents, the coatings appeared clear and transparent when the percentage of the solvents is between 40 and 50 percent in the coatings formulation (Figures 5(a) and 5(b)). When the silane percentage is too high or more than 60 percent, the dried coating cracked and flaked due to the high density of the cross-linking causing the brittleness of the coating layer (Figures 4(a) and 4(b)). However, when the solvents percentage is too high or higher than 60 percent, the coatings become hazy due to the rough surface formed, and the binder is not enough to cover the whole substrate (Figures 6(a) and 6(b)).

Figures 7 and 8 show the values of haze and percentage of light diffused from the coated samples. The best haze values was obtained from the sample that was mixed with $\mathrm{N}$ propanol $50 \%$ and silane binder $50 \%$ which is $0.38 \%$ of haze values and $0.34 \%$ of light diffused throughout the samples (Figure 7). Comparatively, all the haze values and the light diffused from the mixture of silane and ethanol samples were higher compared to the sample that was mixed with the 50\% of N-propanol and silane (Figures 7 and 8).

Figure 9 shows that the haze values of the samples increase as the amount of nanoparticles increased. The lowest value was obtained from the sample that was mixed with silver nanoparticles $0.5 \%$. Zinc oxide and titanium dioxide gave higher haze values due to the hiding strength character of the particles that is higher compared to silver. Zinc oxide and titanium dioxide are widely used in paint industry as pigments.

\section{Conclusion}

We managed to prepare transparent silica-based aerogels using methyltrimethoxysilane with various alcohols as a solvent. The solvents play important roles in producing a high-transparency film by giving sufficient time for the polymer network to form the aerogel. With an optimum amount of solvent and precursors we manage to get a clear silica-based coating without sacrificing the hardness of the coating film. We found out that $1: 1$ ratio is the optimum ratio between methyl trimethoxy silane and N-propanol to obtain a clear dried film with the highest scratch hardness and least light diffused through the film. The advantage of this coating system is the "easy-to-apply" concept which can be cured at room temperature and suitable for the retrofitting or adding function to the installed windows in the building. This is due to the simplest techniques and minimum apparatus needed to apply the coatings. This is favourable to improve the quality of the existed glass windows. Haze values of the film incorporated with nanoparticles were also 

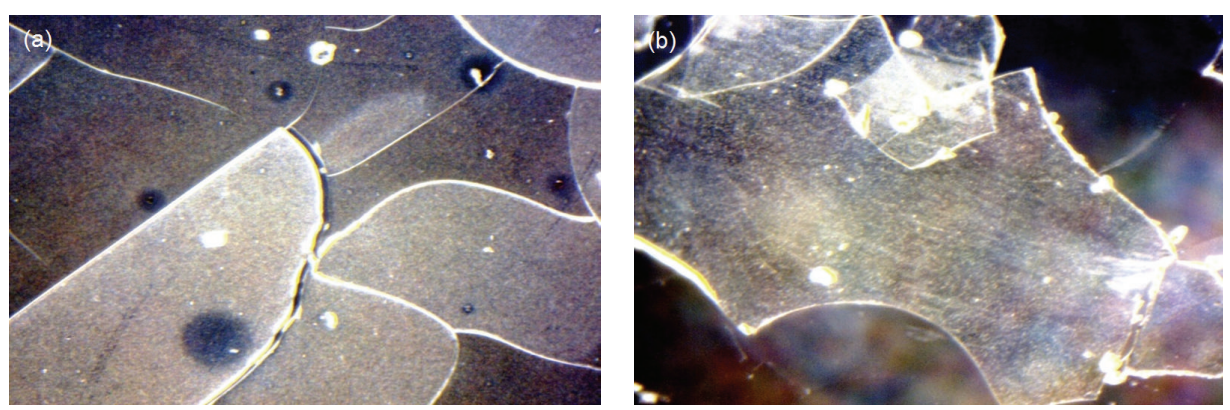

Figure 4: The 500x magnification of the coating surface of coatings from sample (a) 20N and (b) 20E.
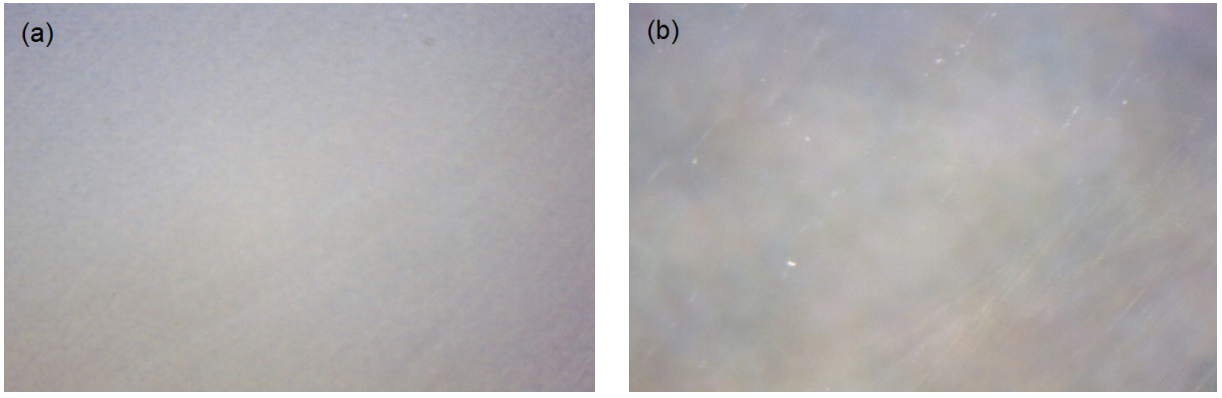

Figure 5: The 500x magnification of the coating surface of coatings from sample (a) 50N and (b) 50E.
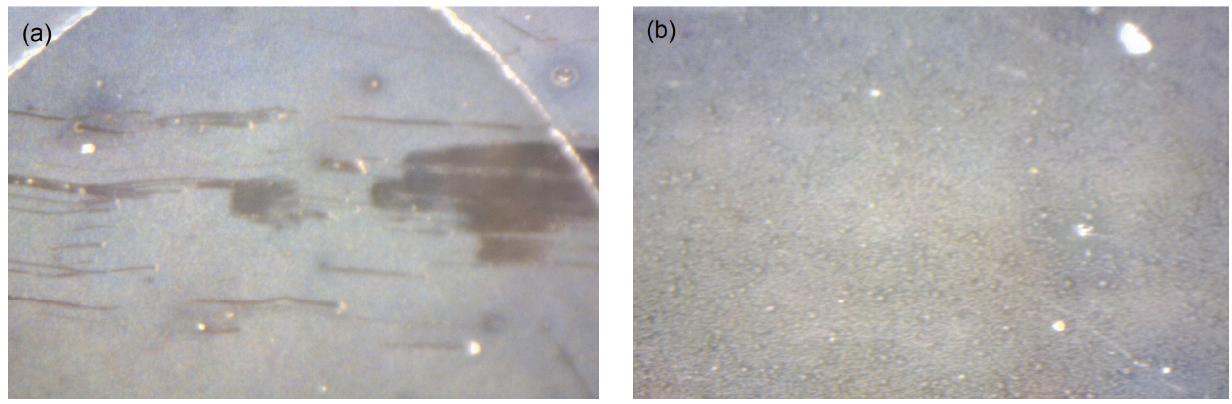

FIGURE 6: The 500x magnification of the coating surface from sample (a) $90 \mathrm{~N}$ and (b) $90 \mathrm{E}$.

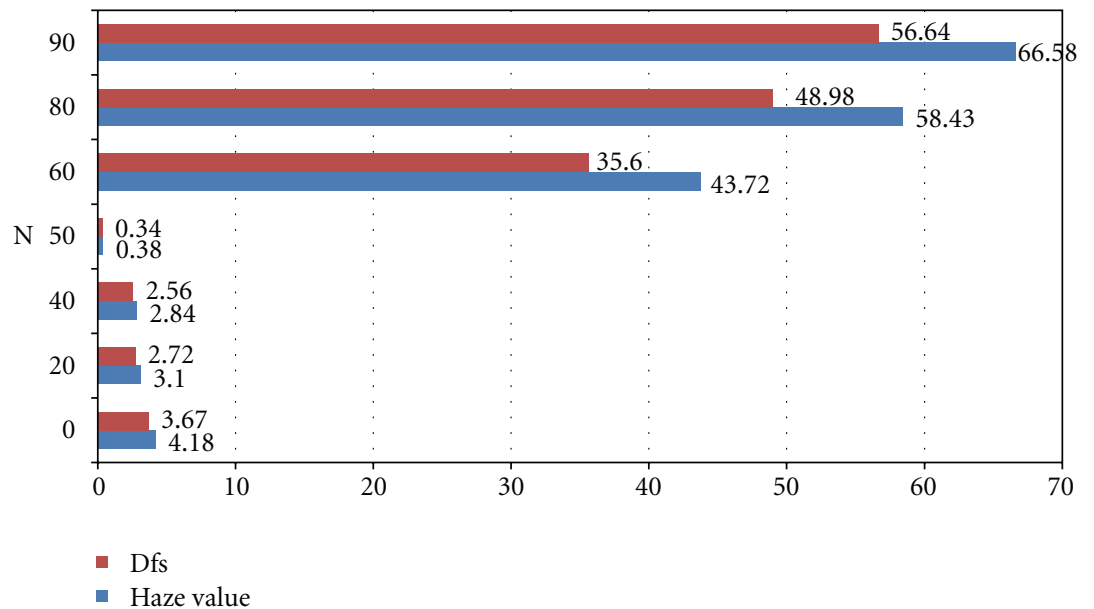

FIGURE 7: The haze values and percentage of light diffused of the dried sol-gel from the mixture of silane and N-propanol. 


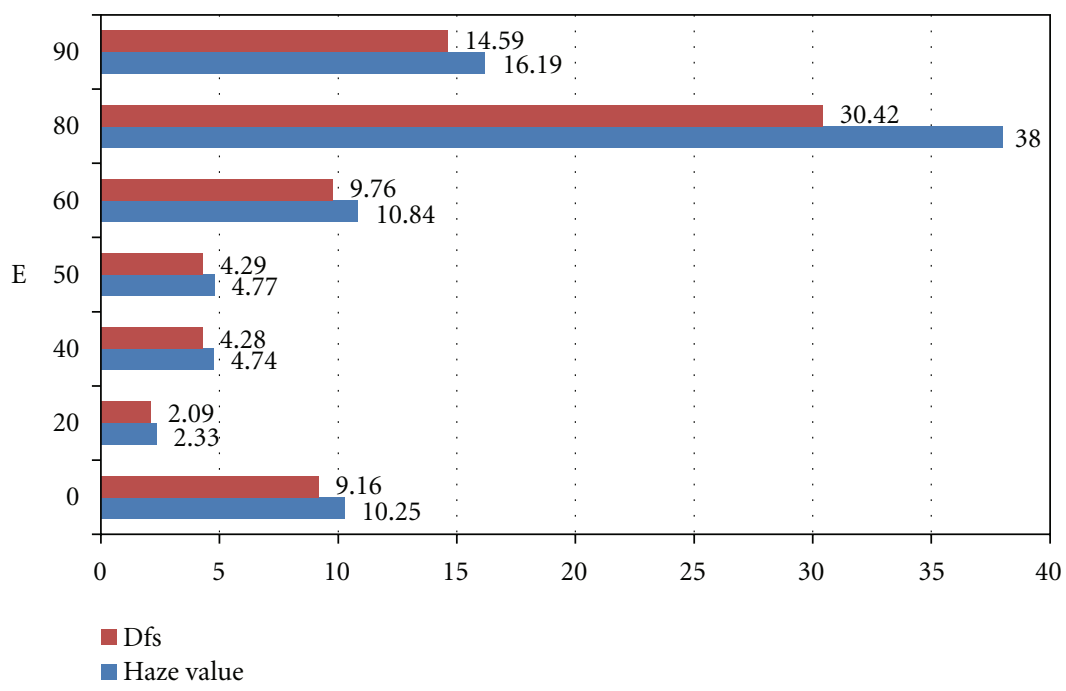

FIgURE 8: The haze values and percentage of light diffused of the dried sol-gel from the mixture of silane and ethanol.

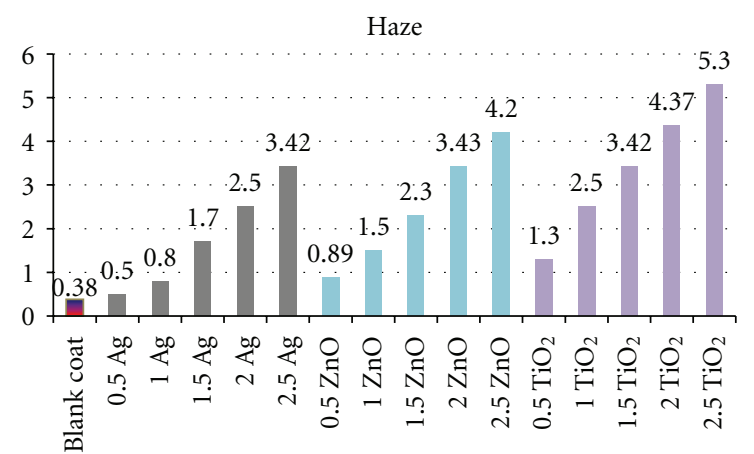

FIGURE 9: Haze values of the sol-gel film mixture with nanoparticles of silver $(\mathrm{Ag})$, zinc oxide $(\mathrm{ZnO})$, and titanium dioxide $\left(\mathrm{TiO}_{2}\right)$.

measured, and silver nanoparticles gave relatively lower haze values compared to zinc oxide and titanium dioxide.

\section{References}

[1] A. Venkateswara Rao and G. M. Pajonk, "Effect of methyltrimethoxysilane as a co-precursor on the optical properties of silica aerogels," Journal of Non-Crystalline Solids, vol. 285, no. 1, pp. 202-209, 2001.

[2] B. J. Privett, J. Youn, S. A. Hong et al., "Antibacterial fluorinated silica colloid superhydrophobic surfaces," Langmuir, vol. 27, no. 15, pp. 9597-9601, 2011.

[3] V. V. Ganbavle, U. K. H. Bangi, S. S. Latthe, S. A. Mahadik, and A. V. Rao, "Self-cleaning silica coatings on glass by single step sol-gel route," Surface and Coatings Technology, vol. 205, no. 23-24, pp. 5338-5344, 2011.

[4] K. Banger, Y. Yamashita, K. Mori et al., "Low-temperature, high-performance solution-processed metal oxide thin-film transistors formed by a "sol-gel on chip" process," Nature Materials, vol. 10, no. 1, pp. 45-50, 2010.

[5] D. Y. Nadargi, S. S. Latthe, and A. Venkateswara Rao, "Effect of post-treatment (gel aging) on the properties of methyltrimethoxysilane based silica aerogels prepared by twostep sol-gel process," Journal of Sol-Gel Science and Technology, vol. 49, no. 1, pp. 53-59, 2009.

[6] A. Agrawal and J. P. Cronin, "The merits of Sol-Gel processing for electrochromic windows: a commercial perspective," SolGel Processing for Conventional and Alternative Energy, pp. 275-291, 2012.

[7] A. Cannavale, F. Fiorito, M. Manca, G. Tortorici, R. Cingolani, and G. Gigli, "Multifunctional bioinspired sol-gel coatings for architectural glasses," Building and Environment, vol. 45, no. 5, pp. 1233-1243, 2010.

[8] R. Prado, G. Beobide, A. Marcaide, J. Goikoetxea, and A. Aranzabe, "Development of multifunctional sol-gel coatings: anti-reflection coatings with enhanced self-cleaning capacity," Solar Energy Materials and Solar Cells, vol. 94, no. 6, pp. 10811088, 2010.

[9] S. Ilican, Y. Caglar, M. Caglar, and F. Yakuphanoglu, "Structural, optical and electrical properties of F-doped $\mathrm{ZnO}$ nanorod semiconductor thin films deposited by sol-gel process," Applied Surface Science, vol. 255, no. 5, pp. 2353-2359, 2008.

[10] D. Wang and G. P. Bierwagen, "Sol-gel coatings on metals for corrosion protection," Progress in Organic Coatings, vol. 64, no. 4, pp. 327-338, 2009.

[11] N. Avci, P. F. Smet, J. Lauwaert, H. Vrielinck, and D. Poelman, "Optical and structural properties of aluminium oxide thin films prepared by a non-aqueous sol-gel technique," Journal of Sol-Gel Science and Technology, vol. 59, no. 2, pp. 327-333, 2011.

[12] D. Fregonese and F. Costa, "Sol gel process for producing protective films for polymeric substrates," EP patent 1,935, 929, 2011.

[13] O. Bunkoed, F. Davis, P. Kanatharana, P. Thavarungkul, and S. P. J. Higson, "Sol-gel based sensor for selective formaldehyde determination," Analytica Chimica Acta, vol. 659, no. 1-2, pp. 251-257, 2010.

[14] S. B. Lee, I. C. Jang, H. H. Lim, V. Aravindan, H. S. Kim, and Y. S. Lee, "Preparation and electrochemical characterization of $\mathrm{LiFePO}_{4}$ nanoparticles with high rate capability by a sol-gel method," Journal of Alloys and Compounds, vol. 491, no. 1-2, pp. 668-672, 2010. 
[15] M. C. Tsai, J. C. Chang, H. S. Sheu, H. T. Chiu, and C. Y. Lee, "Lithium ion intercalation performance of porous laminal titanium dioxides synthesized by sol-gel process," Chemistry of Materials, vol. 21, no. 3, pp. 499-505, 2009.

[16] W. Zhou, R. Ran, Z. Shao, W. Jin, and N. Xu, "Synthesis of nano-particle and highly porous conducting perovskites from simple in situ sol-gel derived carbon templating process," Bulletin of Materials Science, vol. 33, no. 4, pp. 371-376, 2010.

[17] K. Farrington and F. Regan, "Molecularly imprinted sol gel for ibuprofen: an analytical study of the factors influencing selectivity," Talanta, vol. 78, no. 3, pp. 653-659, 2009.

[18] C. J. Brinker and G. W. Scherer, Sol-Gel Science: The Physics and Chemistry of Sol-Gel Processing, Academic Press, 1990.

[19] C. Reichardt and T. Welton, Solvents and Solvent Effects in Organic Chemistry, Wiley-VCH, 2011. 

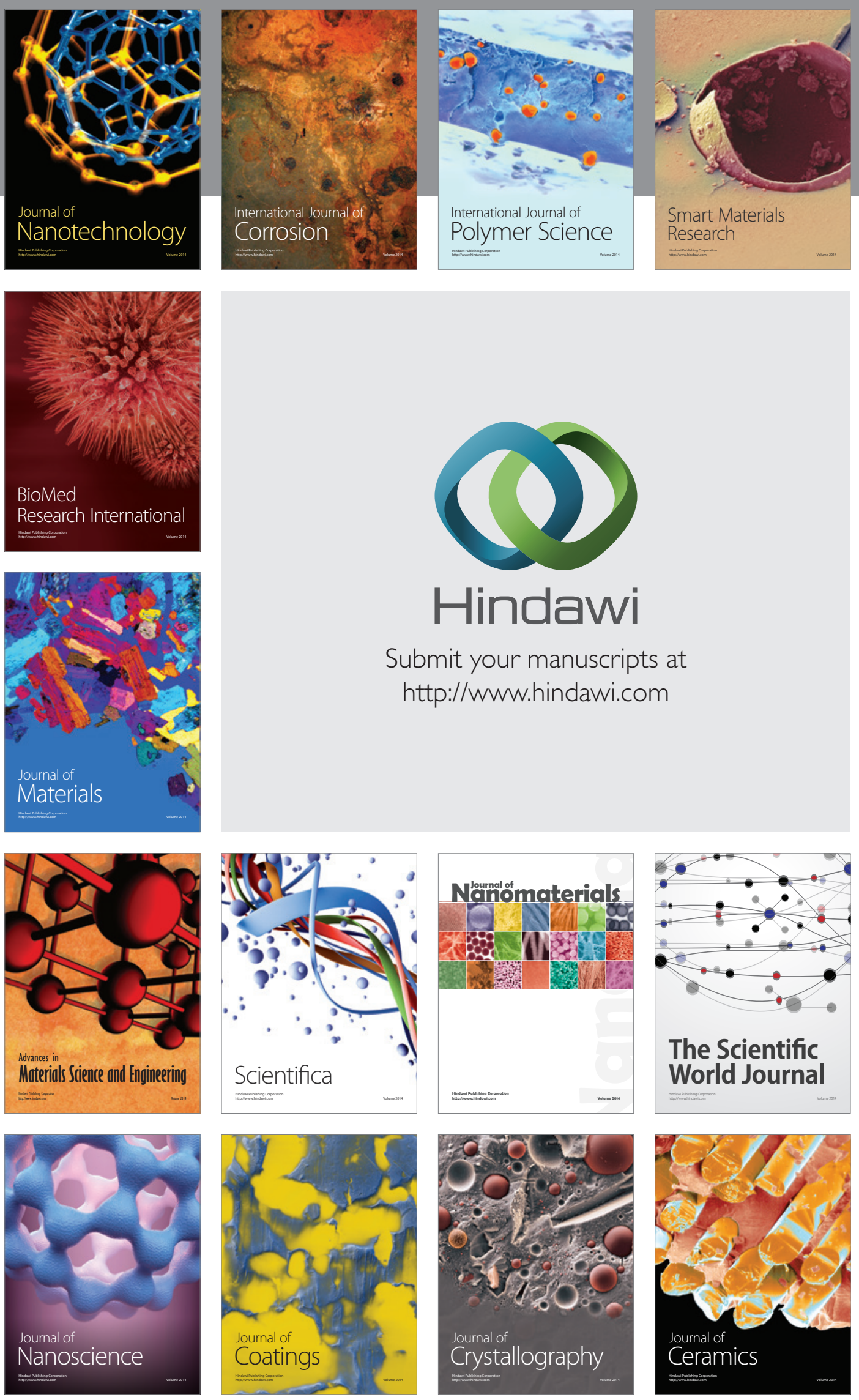

The Scientific World Journal

Submit your manuscripts at

http://www.hindawi.com

\section{World Journal}

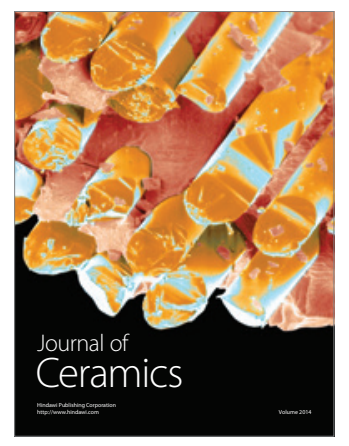

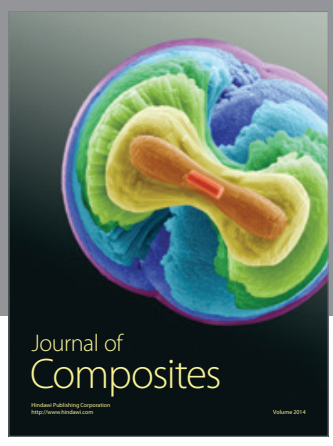
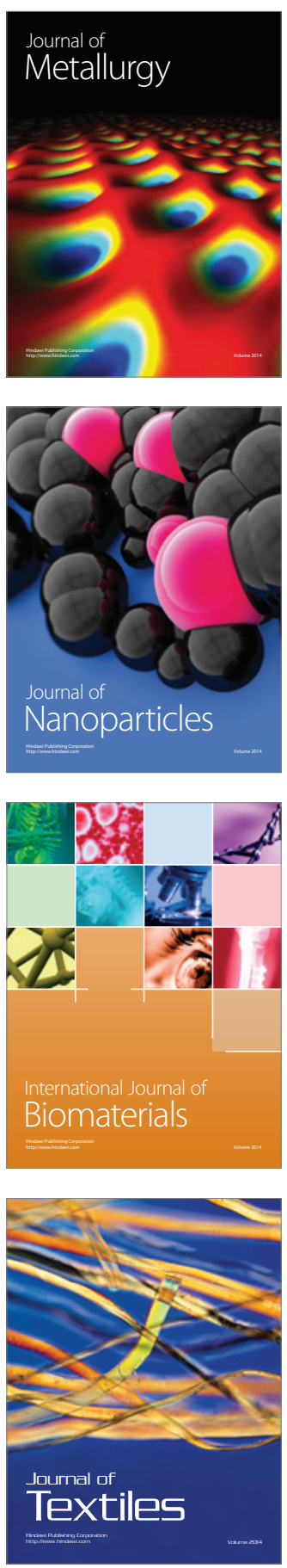